\title{
RECONTEXTUALIZAÇÃO DIDÁTICA DA EXPOSIÇÃO CIÊNCIA, RAÇA E LITERATURA EM SEQUENCIAS DIDÁTICAS VOLTADAS À EDUCAÇÃ̃o DAS RELAÇÕES ÉTNICO-RACIAIS POR PROFESSORES DA EDUCAÇÃO BÁSICA.
}

\author{
$\underline{\text { Rosangela dos Santos Nóbrega }}{ }^{1}$; Cláudia Alencar Serra e Sepulveda ${ }^{2}$ \\ 1. Bolsista PIBIC/CNPq, Graduando em Licenciatura em Ciências Biológicas, Universidade Estadual de Feira de \\ Santana, e-mail: rosangellanobrega@gmail.com \\ 2. Orientador, Departamento de educação, Universidade Estadual de Feira de Santana, \\ e-mail: sepulveda.cau@gmail.com
}

PALAVRAS-CHAVE: racismo científico, educação das relações étnico-raciais, pesquisa de planejamento.

\section{INTRODUÇÃO}

A exposição Ciência, Raça e Literatura resultou de um trabalho colaborativo entre estudantes da Licenciatura em Ciêncais Biológicas da UEFS e pesquisadores em ensino, filosofia e história das ciências da UFBA e UEFS, e teve a curadoria coletiva de suas nove edições alimentadas por estudos sobre racismo científico, em grande parte gerados no âmbito do projeto "Investigação em Inovações Educacionais em Ensino de Evolução e Genética com abordagem Ciência, Tecnologia e Sociedade” ( CONSEP ). Ao longo desta itinerância, as temáticas abordadas na exposição têm sido apropriadas por comunidades escolares que a visitam, dando origem ou incorporando-se a projetos pedagógicos e intervenções educacionais voltados para relações étnico-raciais. Com efeito, a exposição é de suma importância para a construção de uma demanda curricular que atenda às necessidades sobre o ensino dos povos africanos, pois esta tem o potencial de promover uma visão crítica do conceito de raça e de sua relação com a ciência e práticas de alterização, contribuindo de forma ímpar para educação das relações étnicoraciais. Nessa perspectiva, tendo em vista que apesar de dez anos de promulgada, a lei 10.639/2003 ainda encontra uma série de obstáculos para um maior enraizamento e institucionalização nas escolas e sistemas de ensino e, além disso, apesar de existirem práticas pedagógicas que tratam do tema em questão, estas ainda são insuficientes para atender a demanda de ensino das Relações Étnico-Raciais, nesta pesquisa o presente trabalho visou identificar Como texto da quinta e sexta edição da exposição Ciência, Raça e Literatura foi recontextualizado em propostas pedagógicas de ensino de História e Biologia pelas professoras da educação básica,de uma escola da rede estadual de ensino de Feira de Santana? 


\section{MATERIAL E MÉTODOS OU METODOLOGIA (ou equivalente)}

Para compreender como os professores têm recontextualizado as temáticas da exposição Ciência, Raça e Literatura para o trabalho em sala de aula, foi necessários duas etapas ou instâncias de coleta e organização de dados: (1) a construção de um texto que descreve o acervo da exposição - os temas e como são organizados e apresentados em instalações, artefatos e textos apresentados ao público; e (2) procedimentos de coleta de informações acerca de como as professoras os introduziram e transformaram em conteúdos curriculares e atividades pedagógicas. Para tanto, foram analisados registros audiovisuais de uma apresentação de relato de experiência em seminário na UFBA por duas professoras, acerca de planejamento e realização de atividades em sala de aula de Biologia e História que antecederam e culminaram do projeto "Consciência Negra" de uma comunidade

escolar e realizadas entrevistas semi-estruturadas com essas professoras.

Para a construção do texto que descreve o acervo da exposição, tomou-se a descrição feita pelos curadores do acervo que foi exposto na 5 e 6 edições, a partir da descrição de cada um dos elementos que o compunham encontrada em Dias (2017).

Foi desenvolvida uma estrutura teórica- metodológica baseada nos conceitos da teoria dos códigos de Basil Bernstein (BERNSTEIN,1996) para analisar os dados oriundos destas fontes de modo a identificar os princípios que orientaram as professoras na recontextualização do texto da referida exposição em propostas pedagógicas voltadas a educação das relações étnico-raciais no ensino médio de Biologia e História. Essa estrutura encontra-se estruturada nas categorias de classificação e enquadramento, as quais veiculam e distribuem as relações sociais de poder e controle. A classificação refere-se ao grau de manutenção de fronteiras entre categorias (por exemplo, professores, estudantes, espaços, conteúdos de aprendizagem, disciplinas, escola, comunidade, movimentos sociais) e é considerada forte quando há uma nítida separação ou isolamento entre essas categorias. Quando a classificação é forte $(+C)$ as categorias são separadas por limites fortes e quando a classificação é fraca (-C), há uma redução nas fronteiras entre as categorias. $O$ enquadramento refere-se às relações sociais dentro das categorias, por exemplo, relações no interior da escola, da comunidade, da família, da igreja e etc.. É considerado forte (+E) quando os sujeitos com status social superior dentro de uma categoria (por exemplo, o professor em relação aos estudantes ou os pais em relação aos filhos) detêm, sozinhos, o controle sobre as relações que nela se estabelecem, e é considerado fraco (-E) quando os sujeitos com status inferior têm alguma forma de controle nessa mesma relação.

\section{RESULTADOS E/OU DISCUSSÃO (ou Análise e discussão dos resultados)}

Foram analisadas as relações entre discursos presentes no processo de recontextualização, correspondente ao "o que do discurso pedagógico, tal análise visou identificar especificamente as categorias: interdisciplinaridade e discurso dos movimentos sociais/ ciências.Outro componente analisado seria a relação entre sujeitos, especialmente professores e alunos, correspondente ao "como" do discurso pedagógico. Tal análise visou identificar especificamente as categorias: seleção e seqüenciamento. O mapa conceitual abaixo indica os aspectos selecionados para a análise do processo de transformação do discurso pedagógico. 


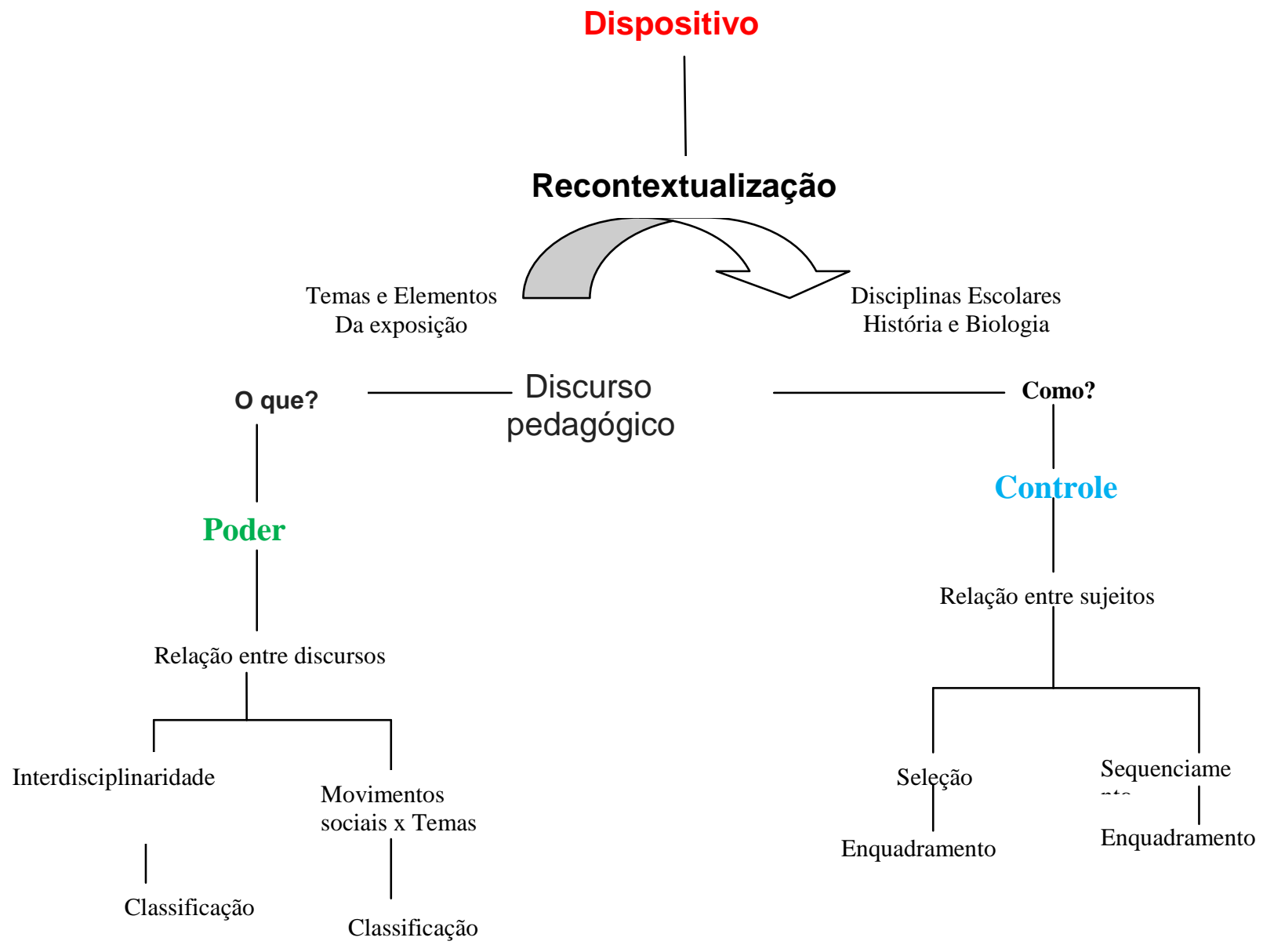

Figura 1 - Aspectos selecionados para a análise do processo de transformação do discurso pedagógico

O quadro abaixo sintetiza o que foi apontando de maneira geral como em cada seção da Exposição Ciência, Raça e Literatura pôde se relacionar com as disciplinas da educação básica, mostrando dentro de cada seção específica como a interdisciplinaridade pode ser identificada em trechos da caracterização de tal exposição/edição.

\begin{tabular}{|c|c|}
\hline Seção & Disciplinas relacionadas \\
\hline Exposições antropológicas - Zoológicos & \\
\hline humanos & Biologia \\
\hline Teorias Raciais e Identidade Nacional & $\begin{array}{c}\text { Biologia, História e Literatura } \\
\text { História e Literatura }\end{array}$ \\
\hline A questão racial na literatura nacional & Biologia \\
\hline $\begin{array}{l}\text { "Nova Genética" e o estatuto científico do } \\
\text { conceito de raca }\end{array}$ & Biologia \\
\hline $\begin{array}{l}\text { Biomédicas e racismo científico } \\
\text { contemporâneo }\end{array}$ & Biologia \\
\hline
\end{tabular}

Quadro 1. Síntese das relações interdisciplinares evidenciadas, de forma geral, no texto da Exposição Ciência, Raça e Literatura.

A abordagem do texto da prática pedagógica evidenciou um diálogo entre as disciplinas de Biologia e História como mostrado abaixo: 


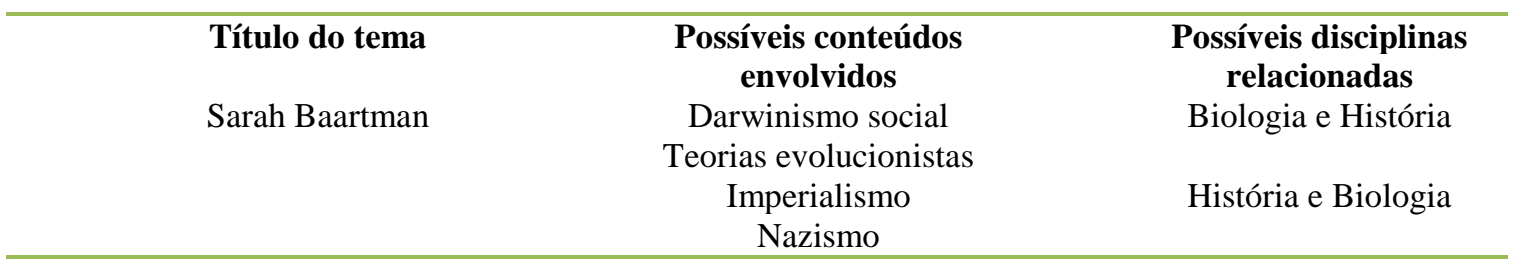

Quadro 2 . Relações interdisciplinares sugeridas no planejamento pedagógico das professoras da educação básica

O uso do filme, Venus Noire, como recurso que permite o diálogo entre as disciplinas de Biologia e História se mostrou uma ferramenta pedagógica muito rica, evidenciando variações nos tipos de classificação entre forte e fraca, como exemplificado abaixo:

Professora A: ... eles fizeram numa sala uma linha do tempo/ da questão do racismo/ como ele foi construído/ o racismo científico no século XIX/ ai tem uma parte que eles botam simulando o diálogo entre Manuel

Quirino e Nina Rodrigues/ Depois eles botam desconstrução do conceito de raça pela ciência contemporânea/

No trecho acima fica evidente um exemplo de enfraquecimento na classificação (C-) , uma vez que, ao contextualizar a abordagem do conceito de raça pela ciência contemporânea com diálogos cientistas/ intelectuais que inferência ao discurso histórico- social da época, traz um forte indicio de interdisciplinaridade na prática pedagógica.

\section{CONSIDERAÇÕES FINAIS (ou Conclusão)}

O uso do dispositivo teórico de Basil Bernstein se mostrou como um instrumento bastante rico para evindenciar como se procedeu o processo pedagógico das professoras, além disso, foi possível evidenciar que uso dos temas e artefatos da exposição permitiu aos professores mediarem o processo de ensino, dentro das temáticas voltadas para a educação das relações étnico- raciais, de uma forma mais enriquecedora, possibilitando a quebra de poder e controle durante a prática pedagógica, motivando os alunos a pensarem e se posicionar diante dos discursos hegemônicos que the são ensinados, principalmente o discurso científico.

\section{REFERÊNCIAS}

BERNSTEIN, B. A estruturação do discurso pedagógico: classe, códigos e controle. Petrópolis: Vozes. 1996.

DIAS, T. L. da S. Ciência, raça e literatura: as contribuições de uma exposição itinerante para educação das relações étnico-raciais. Dissertação (Mestrado em Ensino, Filosofa e História das Ciências) Instituto de Física. Universidade Federal da Bahia. Salvador. 2017 DIAS, T. L. da S. Ciência, raça e literatura: as contribuições de uma exposição itinerante para educação das relações étnico-raciais. Dissertação (Mestrado em Ensino, Filosofa e História das Ciências) Instituto de Física. Universidade Federal da Bahia. Salvador. 2017 . 